\title{
Enzyme amplified immunoassay: a novel technique applied to direct detection of Chlamydia trachomatis in clinical specimens
}

\author{
SF PUGH, ${ }^{*}$ RCB SLACK,${ }^{*}$ EO CAUL, $\dagger$ ID PAUL,$\dagger$ PN APPLETON $\dagger \dagger S$ GATLEY $\dagger \dagger$
}

From the *Department of Microbiology and Public Health Laboratory Service Laboratory, University Hospital, Queen's Medical Centre, Nottingham, the †Joint Regional Public Health Laboratory Service and District Virology Laboratory, Bristol, and ††IQ (BIO) Limited, Cambridge.

SUMMARY Endocervical swabs from 212 women and urethral swabs from 100 men were tested by the routine methods for McCoy cell culture and simultaneously by a novel enzyme amplified immunoassay test to detect chlamydia antigen. Overall correlation of the amplified test with culture was $96.5 \%$. The test proved to be a suitable screening procedure for genital chlamydial infection, particularly for large numbers of specimens or in cases in which culture was not available.

The recognition of Chlamydia trachomatis as an important human pathogen has led to a greatly increased demand for laboratories to provide a diagnostic service for this organism. The current technique of isolation in cell culture is technically demanding and requires at least 48-72 hours for a result.

Solid phase enzyme linked immunoassays (ELISAs) have been described as ideal procedures for semiautomated mass screening tests. They have proved in some cases, however, to be insufficiently sensitive to replace culture, particularly when low numbers of micro-organisms are present, because they lack the multiplication of antigen inherent in a culture process.

We report the application of a novel enzyme amplification procedure used in the development and production of a rapid sensitive diagnostic test for $C$ trachomatis.

In a conventional "sandwich" ELISA an enzyme-antibody conjugate reacts directly with a suitable substrate to give a coloured product. The enzyme amplified immunoassay differs from the conventional assay in that it has an amplification process in two stages and uses two separate enzyme systems. In the first of these the substrate nicotinamide adenine dinucleotide phosphate (NADP) is converted to nicotinamide adenine dinucleotide (NAD) by the action of alkaline phos-

Accepted for publication $11 \mathrm{June} 1985$ phatase conjugated to a monoclonal antibody. The subsequent addition of a secondary enzyme system permits the interconversion of NAD to its reduced form (NADH) by alcohol oxidoreductase. A second enzyme diaphorase regenerates the NAD (Figure).

During this cyclical process one molecule of NAD triggers the production of many molecules of the coloured product, formazan, which greatly increases the sensitivity of the test. The amplification "gain" of such a system depends on the relative concentrations and activities of the enzyme used. The reagents used in this test have been standardised to achieve a gain of about $500 \times$. Details concerning a comparison between non-amplified and amplified procedures will be published elsewhere. ${ }^{1}$

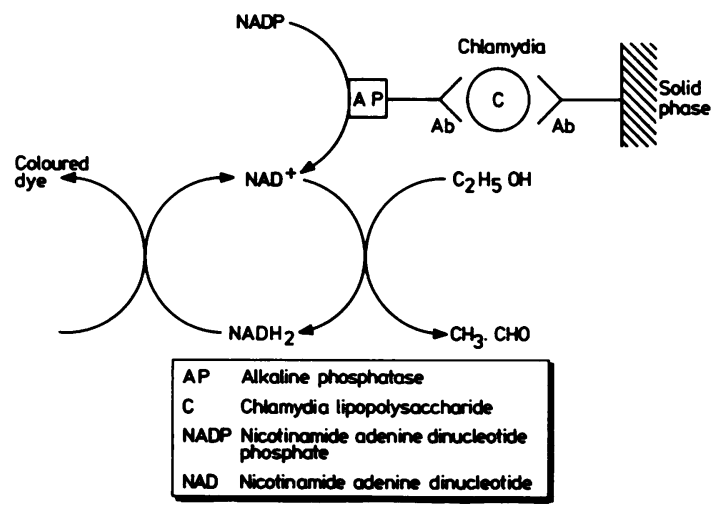

Enzyme amplified immunoassay with amplification process in two stages. 
Table 1 Results of tests by enzyme amplified immunoassay and culture for $C$ trachomatis on genital tract swabs collected from 212 women and 100 men

\begin{tabular}{|c|c|c|c|c|}
\hline & \multirow{2}{*}{$\begin{array}{l}\text { Enzyme amplified } \\
\text { immunoassay results }\end{array}$} & \multicolumn{3}{|c|}{ Cell culture results } \\
\hline & & Positive & Negative & Total \\
\hline Bristol men* & $\begin{array}{l}\text { Positive } \\
\text { Negative }\end{array}$ & $\begin{array}{r}44 \\
2\end{array}$ & $\begin{array}{r}0 \\
54\end{array}$ & $\begin{array}{l}44 \\
56\end{array}$ \\
\hline \multirow[t]{2}{*}{ Bristol women } & Positive & 25 & 1 & 26 \\
\hline & Negative & 1 & 75 & 76 \\
\hline \multirow[t]{2}{*}{ Nottingham women } & Positive & 19 & 2 & 21 \\
\hline & Negative & 5 & 84 & 89 \\
\hline \multirow[t]{2}{*}{ Total } & Positive & 88 & 3 & \\
\hline & Negative & 8 & 213 & \\
\hline
\end{tabular}

*Patients with postgonococcal urethritis, non-gonococcal urethritis and gonorrhoea, and consorts of patients with known $C$ trachomatis infection.

\section{Material and methods}

The evaluation of the enzyme amplified test in comparison with cell culture for diagnosing $C$ trachomatis was carried out at the public health laboratories in Nottingham and Bristol. Enzyme amplified immunoassay kits were provided by IQ (BIO) Ltd.

Duplicate endocervical or urethral swabs were taken from 212 unselected women and 100 selected men (Table 1) attending the departments of genitourinary medicine. Specimens for the amplified test were all taken using cotton wool swabs on compressed paper sticks (Minitip, Exogen Ltd) and broken off into a special transport medium supplied with the test kit. The other swab was taken and treated according to the routine procedure at that centre for isolating chlamydia in cell culture.

\section{CULTURE}

Swabs for culture were broken off into culture transport medium, Medium 199 with calf serum, sorbitol, glucose, vancomycin, and amphotericin B at Nottingham, or as previously described at Bristol. ${ }^{2}$ Specimens were inoculated into coverslip cultures of either cytochalasin B or McCoy cells treated with cycloheximide. Inocula of $0.25 \mathrm{ml}$ and $0.5 \mathrm{ml}$ and coverslips of $10 \mathrm{~mm}$ and $16 \mathrm{~mm}$ in diameter were used at Bristol and Nottingham, respectively. The inoculum was centrifuged on to the cells for one hour $\left(2000-3000 \mathrm{~g}, 35^{\circ} \mathrm{C}\right)$. Inoculated cultures were incubated at $35-37^{\circ} \mathrm{C}$ for 72 hours, washed, fixed in methanol, stained with Giemsa, and systematically screened by dark ground microscopy for the presence of intracytoplasmic inclusion bodies of $C$ trachomatis.

THE ASSAY

A monoclonal antibody raised against the genus specific lipopolysaccharide antigen of $C$ trachomatis was used to produce microtitre plates coated with antibody as well as an alkaline phosphatase conju- gate (Figure). Lyophilised substrate and amplification reagents, with control materials and concentrated washing buffer, were also supplied.

PREPARATION OF THE SPECIMENS

Specimens were vortex mixed for 15 seconds in their transport medium and then heated at $100^{\circ} \mathrm{C}$ for 15 minutes in a water bath. After cooling the specimens were vortexed for a further 15 seconds. A $200 \mu \mathrm{l}$ volume of specimen extract was placed in duplicate wells in the coated plate. A $100 \mu \mathrm{l}$ volume of positive control material included in the kit was diluted $\overrightarrow{0}$ in $1 \mathrm{ml}$ of transport medium, boiled, and testeg o o together with the specimen extracts. Boiled trans. port medium was included as a negative control. Tkes plate was then incubated at $18-22^{\circ} \mathrm{C}$ in a moist box for two hours. A $50 \mu \mathrm{l}$ volume of conjugated antibody was then added to each well and the plate incubated for a further one hour.

After incubation the wells were washed four times with washing buffer. A $100 \mu$ l volume of fresh NADP solution was added to each well and the plate incubated at $18-22^{\circ} \mathrm{C}$ for 40 minutes. A $20 \mu$ l volume of freshly prepared amplifier solution was then added and the development of colour stopped after $:$ 10 minutes by the addition of $50 \mu \mathrm{l} 0 \cdot 27 \mathrm{M}$ sulphuric 3 . acid well. Optical densities of the wells were then $\delta$ read using a Dynatech MR 580 plate reader with a $490 \mathrm{~nm}$ filter. A cut off point was determined from 0 the mean of the negative controls plus 0.05 absorbance units, and specimens were scored positive or negative accordingly.

Table 2 Overall sensitivity and specificity of enzyme amplified immunoassay compared with culture (\%)

\begin{tabular}{|c|c|c|c|}
\hline & Men & Women & Total \\
\hline $\begin{array}{l}\text { Overall correlation between } \\
\text { amplified enzyme linked } \\
\text { immunoassay and cell } \\
\text { culture }\end{array}$ & 98 & 96 & 96 \\
\hline $\begin{array}{l}\text { Copositivity (sensitivity) } \\
\text { Conegativity (specificity) }\end{array}$ & $\begin{array}{r}96 \\
100\end{array}$ & $\begin{array}{l}88 \\
98\end{array}$ & $\begin{array}{l}92 \\
99\end{array}$ \\
\hline
\end{tabular}


Results

Table 1 shows the results of the comparison between cell culture and enzyme amplified immunoassay. The results gave an overall copositivity of $92 \%$ and a conegativity of $99 \%$ (Table 2 ). When the results were analysed by inclusion numbers we found that enzyme amplified immunoassay tended to miss culture positives with few inclusions, particularly at Nottingham (Tables 3,4 ). In view of this the five culture positive but enzyme amplified immunoassay, negative specimens from Nottingham were retested by enzyme amplified immunoassay together with the corresponding culture transport media. All the specimens in the enzyme amplified immunoassay transport medium again yielded negative results, but three of five of the culture transport media were positive by enzyme amplified immunoassay, two from specimens that gave $>10$ inclusions per coverslip but less than one inclusion per field and one from a specimen that gave one to 10 inclusions per coverslip.

\section{Discussion}

The results of this study showed that the enzyme amplified immunoassay described compared favourably with cell culture for the diagnosis of $C$ trachomatis infections. The isolation rate from men $(46 \%)$ is similar to that found in other studies using a sensitive culture method. ${ }^{3}$ The isolation rate from women $(24 \%)$ is also comparable with that found by other workers ${ }^{4}$ for patients attending clinics for sexually transmitted diseases.

The high overall specificity $(99 \%)$ of the test is attributable to the use of a monoclonal antibody directed against genus specific lipopolysaccharide antigen.5 The sensitivity of $92 \%$ was adequate in a study in which numbers were small. This good correlation was due in part to the fact that the monoclonal antibody detects not only elementary bodies but also

Table 3 Culture positive results analysed by inclusion numbers (Bristol)

\begin{tabular}{clc}
\hline No of inclusions per monolayer & \multicolumn{2}{l}{$\begin{array}{l}\text { Concordant positives/culture } \\
\text { positives }\end{array}$} \\
\cline { 2 - 3 } & Women & Men \\
\hline$>1000$ & $6 / 6$ & $2 / 2$ \\
$100-1000$ & $5 / 5$ & $10 / 10$ \\
$10-100$ & $9 / 10$ & $21 / 21$ \\
$1-9$ & $5 / 6$ & $11 / 13$ \\
\hline
\end{tabular}

Table 4 Culture positive results analysed by inclusion numbers (Nottingham) (Cultures examined at $\times 200$.)

\begin{tabular}{ll}
\hline No of inclusions & $\begin{array}{l}\text { Concordant positives/ } \\
\text { culture positives }\end{array}$ \\
\hline$>5$ per field & $4 / 4$ \\
$1-5$ per field & $5 / 5$ \\
$>10$ inclusions and < per field & $9 / 11$ \\
$1-10$ inclusions per monolayer & $1 / 4$ \\
\hline
\end{tabular}

free lipopolysaccharide antigen. ${ }^{67}$

In any comparison of two swabs taken from the same site there are bound to be discrepancies, particularly when the quantity of antigen is small. This is illustrated by the finding that the culture transport medium from three of five culture positive, but enzyme amplified immunoassay negative specimens was positive by enzyme amplified immunoassay. There were more culture positive at enzyme amplified immunoassay negative specimens at Nottingham than at Bristol. This is unlikely to have been due to differences in performance of the immunoassay as methods between the two centres were standardised and was probably due to differences in cell culture methods: in particular, double the amount of inoculum and a larger coverslip were used at Nottingham.

The advantages of antigen detection tests are threefold: speed of diagnosis; potential for automation; and ease of transport of specimens. The test described can be performed in four hours whereas cull culture takes a minimum of two days before a result can be reported and is technically demanding. Microtitre plate immunoassays can be read by several commercially available plate readers, and many tests can be done in a working day. As the assay is not dependent on the viability of organisms transport of specimens is not critical. This means that large numbers of specimens from different clinics may be stored and batch tested. Enzyme amplification technology appears to be a widely applicable means of increasing the sensitivity of solid phase immunoassays to the point where they are a viable alternative to cell culture.

\section{References}

' Self $\mathrm{CH}$. Enzyme amplification-a general method applied to provide an immunoassisted assay for placental alkaline phosphatase. J Immun Methods (in press).

${ }^{2}$ Richmond SJ. The isolation of Chlamydia sub-group A (C trachomatis) in irradiated McCoy cells. Journal of Medical Laboratory Technology 1974;31:7-9.

${ }^{3}$ Vaughan-Jackson JD, Dunlop EMC, Daroughar S, Treharne JD, Taylor-Robinson $\mathrm{D}$. Urethritis due to $\mathrm{C}$ trachomatis. $\mathrm{Br} \mathrm{J}$ Vener Dis 1977;53:180-3.

4 Persson K, Persson Kristina, Hansson H, et al. Prevalence of nine different microorganisms in the female genital tract. $\mathrm{Br} J$ Vener Dis 1979;55:429-33.

s Thornley MJ, Zamzi SE, Byrne MD, Lusher M, Evans RJ. Properties of monoclonal antibodies to the genus-specific antigen of $C$ trachomatis and their use for antigen detection by reverse passive haemagglutination. J Gen Microbiol 1985.

- Alexander I, Paul ID, Caul EO. Evaluation of a genus-reactive monoclonal antibody for the rapid diagnosis of $\mathrm{C}$ trachomatis by the direct immunofluorescence test. $\mathrm{Br} J$ Vener Dis (in press).

' Caul EO, Paul ID. An ELISA-based assay for the detection of C trachomatis. Lancet 1985; i: 279.

Requests for reprints to: Dr SF Pugh, Department of Microbiology and Public Health Laboratory, University Hospital, Queens Medical Centre, Nottingham NG7 2UH, England. 